\title{
Digital Maturity and Readiness Model for Kazakhstan SMEs
}

\author{
Assel Yezhebay ${ }^{1}$, Venera Sengirova ${ }^{1}$, Dastan Igali $^{1}$, Yasser Omar Abdallah ${ }^{2}$, Essam Shehab ${ }^{1}$ \\ ${ }^{1}$ School of Engineering and Digital Sciences, Nazarbayev University, Nur-Sultan, Kazakhstan \\ essam.shehab@nu.edu.kz, https://nu.edu.kz/faculty/essam-shehab \\ ${ }^{2}$ School of Aerospace, Transport \& Manufacturing, Cranfield University, Cranfield, Bedford, UK \\ Yasser.Abdallah@cranfield.ac.uk, https://www.cranfield.ac.uk/
}

\begin{abstract}
The implementation of digital transformation features is highly required to provide sustainable growth and high level of competitiveness. One of the essential components of the ensuring of SMEs readiness for digital transformation is a digital maturity model that can assess the maturity level based on the features of SMEs in Kazakhstan. This study is focused on the development of digital maturity and readiness model for Kazakhstan SMEs by revision of currently existing digital maturity models, defining the significant features of SMEs in Kazakhstan and developing dimensions, sub-dimensions and levels of the model. The proposed model consists of 6 dimensions and 15 sub-dimensions that are sufficient to assess major dimensions involved in digital transformation. The six layers are used to define the level of digital readiness. The developed model was validated through a survey conducted among 12 managers of the company with approximately 150 employees. The model allowed identifying significant areas for improvement and provided the recommendations for movement to the next maturity level.
\end{abstract} model

Keywords—digital maturity; digital readiness; assessment

\section{INTRODUCTION}

Today, due to the pandemic situation, the global economy falls has become a global challenge. Many countries pay enormous attention to the development of small and medium enterprises (SMEs). They play an essential role in the economy of any country, which is also a necessary key in workplace provision. To make sure the prosperity of SMEs, it is vital to guide their development towards Smart SMEs by using modern progressing technologies. Therefore, it is highly correlated with Industry 4.0 and Digital Transformation. The term digitalization means the adoption of digital or computer technologies by an enterprise to improve or transform business processes [1].

SMEs are viewed as the backbone of the economy in both developed and developing countries [2]. The European Commission defines SME as businesses having less than 250 employees [3]. The research is narrowed down by the criteria scaled to be suitable for Small and Medium Enterprises in Kazakhstan. The characteristics of the SMEs in Kazakhstan are described in Table 1. Also, the research is focused on the development of the maturity model. Maturity is referred to as the meaning of "Ready", "Complete" or achieved the perfect state. A maturity model is defined as current (AS-IS) situations in the organization to enhance improvements along with control of the progress through the roadmap.

For 01.07.2018 in Kazakhstan out of 427,325 registered companies, 424,941 are small and medium enterprises. This number means $99.44 \%$ of all companies are SMEs in Kazakhstan. Also, SMEs contribute to more than $60 \%$ of GDP [4]. Therefore, the country should grow SMEs and make it smarter SMEs using innovative technologies, which also will help them to expand market shares, convert to downstream to be closer to the end-user or customer. For a manufacturing SMEs to develop a digital transformation process, it is necessary to identify levels of digital maturity. A maturity model for Kazakhstani SMEs will provide information in which state of maturity the company is and analyze how many stages of maturity the company is far from a mature state.

This project work intends to develop digital maturity and readiness model for Kazakhstani small and medium enterprises (SMEs) based on their features. The project is aimed to achieve the following objectives:

- To conduct a literature review of papers to identify existing digital maturity models;

- To identify aspects which impact digital maturity in Kazakhstani SMEs;

- To develop digital maturity and readiness model for Kazakhstani SMEs;

- To validate the proposed digital maturity and readiness model for Kazakhstani SMEs by interviewing SME Representative companies.

This work is organized in the following way: Section 1 reviews existing digital maturity assessment model, Section 2 explains the methodology implemented to develop the maturity model for Kazakhstan SME and Section 3 is dedicated to the analysis of the scope, development of dimensions and levels, and assessment method. Section 4 concludes the research study and is followed by Section 8 that describes the areas of further research. 


\section{LITERATURE REVIEW}

The systematic literature review conducted on the research question. Existing maturity and readiness models identified and analyzed in 16 research articles. Out of 16 articles, seven are chosen for further analysis according to the relevance to the small and medium enterprises, number of dimensions, measurement scale, features, country of research origin and limitations

\section{A. Maturity model of digitalization for SME}

The maturity model to measure the level of digitization in SMEs. The model identifies the main aspects which impact the digital maturity of the organization and proposes three levels of maturity from Level 1 to Level 3 in order to evaluate six dimensions described in the following paragraphs.

There are six dimensions to assess to identify its digital maturity level with identified weights for each dimension. They are strategy and leadership, company culture and organization, IT infrastructure, data maturity, process and operations, and product [5].

The maturity level is identified by using of 5-point Likert scale ranges between "Totally disagree to Totally agree" for each dimension described above. The result for each dimension could be calculated by finding the arithmetic mean of all provided ratings for the same dimension.

\section{B. Connected Enterprise Maturity model}

The Connected Enterprise Maturity model was proposed by Rockwell automation in 2014. The focus of the model is on manufacturing companies with the lowest level of maturity to the mature stage holders, which frequently correspond to the small and medium enterprises at different stages of enterprise lifecycle. According to the model, it is essential to concentrate attention to the collaboration across the enterprise by linking processes, people and facilities using Information technologies. The article is not focused precisely on SME. However, still applicable since explanations of the stages refer to the companies at formation and growth stages, which lead to the assumption of applicability from SMEs. According to the article, the enterprise is in a mature stage when it is a connected enterprise. There are five stages defined in the article: assessment, secure and upgraded network and controls, defined and organized working data capital, analytics and collaborations.

In the assessment stage, the model assesses the network between operations technology and information technology using four dimensions: hardware and software, controls and devices, network that move all information and security policies [6].

\section{IMPULS maturity model}

The IMPULS "Industry 4.0 Readiness" model was developed by IMPULS Foundation of the German Engineering Federation. It was primarily dedicated to the Assessment of manufacturing and mechanical engineering companies. The model consists of six dimensions: employees, strategy and organization, smart factory, smart operations, data driven services and smart products.

The six dimensions are applied for the development of a six-level model (from 0 to 5) each of which contains the minimum requirements for movement to the next level. In this system, Level 0 is the companies unprepared for implementation of digitalization activities, and Level 5 are top performers that show all features of digital maturity.

Hamidi et al. (2018) applied the IMPULS model for Assessment of the Malaysian SMEs via questionnaires that were distributed via email to more than 250 companies from various industries [7]. The representatives of companies weighted the score of dimensions by themselves, and the average result was taken for further Assessment. The study showed that overall, the SMEs in Malaysia has a lack of knowledge required for digitalization primarily in the field of datadriven services, strategy and smart factory.

\section{Towards a Maturity Model for Industry 4.0}

The maturity model aims to help companies to apply technologies related to Industry 4.0 and as result guide to enhancing capabilities. Therefore, model concentrates on capabilities of the company in a standardized and repetitive manner and helps to draw a roadmap to reach a more mature state.

It describes 2D relation between capability and aspect dimensions. Capability dimension, as described above, refers to the capabilities of the company. It includes following levels from level zero to level six in total "incomplete, performed, managed, established, predictable, optimizing". Aspect dimension includes subdimensions such as "asset management, data governance, application management, process transformation, organizational alignment".

\section{E. Smart Manufacturing Maturity Model for SMEs $\left(S M^{3} E\right)$}

The $\mathrm{SM}^{3} \mathrm{E}$ maturity model is a three-axis model that consists of five critical organizational dimensions ( $\mathrm{x}$ axis) related to the manufacturing operations, modular toolkit (y-axis) including seven toolboxes, and five maturity levels (z-axis).

In this $\mathrm{SM}^{3} \mathrm{E}$ maturity model, the five organizational dimensions, including finance, people, strategy, process, and product, were selected from the SME perspective. The toolkit is a collection of techniques and practices that lead to the desired goal. The modular toolkit of the model considers the following seven toolboxes: (1) manufacturing toolbox; (2) design and simulation toolbox; (3) robotics and automation toolbox; (4) sensors and connectivity toolbox; (5) cloud/storage toolbox; (6) data analytics toolbox; (7) business management toolbox. The five basic maturity levels for 
SMEs were considered in this model that include: Novice, Beginner, Learner, Intermediate, and Expert [2].

\section{F. The System Integration Maturity Model Industry 4.0 (SIMMI 4.0)}

The SIMMI 4.0 is aimed to determine the readiness of the SMEs for Industry 4.0 in terms of the IT system landscape. This maturity model assesses the IT performance of the enterprise in terms of four dimensions, including vertical integration, horizontal integration, digital product development, and crosssectional technology criteria. Overall, the five maturity stages were considered in this model, including basic digitization level (stage 1), cross-departmental digitization (stage 2), horizontal and vertical digitization (stage 3), full digitization (stage 4), optimized full digitization (stage 5). There are formulae to compute the maturity stage of each dimension based on the questionnaire. The overall maturity level is found by calculating the arithmetic mean of the maturity levels of all dimensions. This maturity model has been applied to six companies coming from the manufacturing, system engineering/consulting, service provider/tax consultant, and commerce sectors [8].

\section{G. The Three-Stage Maturity Model in SMEs towards Industry 4.0}

The Three-Stage Maturity Model is aimed to improve the diversification capabilities of the SME towards Industry 4.0. The SMEs can diversify in several ways; however, this model considers the diversification that involves the participation of the same company in several business sectors.

The Three-Stage Maturity Model is composed of three stages, including envision, enable, enact which guide and train SMEs for diversification opportunities. The maturity scale for each stage is defined with the five levels: initial (level 1), managed (level 2), defined (level 3), transform (level 4), and detailed BM (Business Model) (level 5) [9].

\section{H. Industry 4.0 Maturity Model}

The maturity model includes the following nine dimensions: "strategy, leadership, customers, products, operations, culture, people, governance and technology". Each dimension corresponds to the implementation of Industry 4.0 concepts by checking the resources, the willingness of management and leaders, interaction with customers, collection and utilization of data, use of technologies, knowledge sharing and more. Listed dimensions divided further into 62 subdimensions and after Assessment of maturity level model corresponds to one of the available in the model 1-5 levels of maturity. Level 5 is considered as the highest level of digital maturity in the company and shows conformance with concepts of Industry 4.0. The model utilizes a Likertscale measurement scale after the performance of the surveys.

\section{METHODOLOGY}

As a tool that can be used as a guide for the transformation process, maturity model has the following typical characteristics:

- Dimensions are specific capability areas that are further specified using subareas;

- Levels are states of maturity in a particular dimension and have a distinguishing descriptor;

- Principles of maturity are divided into continuous (scoring at different levels) and staged (specify goals to reach a certain level);

- Assessment approach can be either qualitative with the use of descriptions or quantitative (with Likert scale, e.g.).

The basic Maturity model development process proposed by Lahmann (2010) is used in this study [10]. It was adapted to fulfil the purposes of the research. The final version consists of the following stages:

1. Scope. This phase aims to identify the audience on which the model will focus. At this stage, the features and desires of stakeholders must be specified to determine model requirements.

2. Design. The design phase determines the concept of maturity, the structure of the level system, dimensions and sub-dimensions if any with complete descriptions. In the study, a bottom-up approach is used that means that MM firstly specify dimensions and maturity characteristics and only then derive a description of the corresponding maturity levels.

3. Populate. This stage defines the Assessment tools of the MM and specifies the applied instruments.

\section{MODEL DEVELOPMENT}

\section{A. Scope}

The implementation of Industry 4.0 features is an indispensable component of economic and market models improvement, as it is stated in "Development Strategy Kazakhstan 2050" [11]. In 2017, Ministry for Investments and Development depicted the following features of the Kazakhstani industrial enterprises: approximately $80 \%$ of enterprises in the manufacturing sector (mechanical engineering, metallurgy, etc.) are at the level of Industry 2.0 that is semiautomated manufacturing, while the percentage of companies showing the features of Industry 3.0 is $3 \%$. The rest of the companies is at the transitional level. The Assessment was made based on the level of technologies, strategy and management, production and organization, personnel and communication [12].

The main identified challenges and barriers are a lack of qualified specialists, financial support, telecommunication infrastructure development, low level of local competences and limited understanding of necessity lying behind digital transformation. However, this study was focused on large enterprises such as 
Eurasian Foods JSC, Kentau Transformer Plant JSC, etc. So, there is evidence for lack of attention towards digitalization of SMEs in the Republic of Kazakhstan.

According to the results of 2019, SMEs with the overall number of 1.186 million contributed $28 \%$ to GDP of Kazakhstan. This number gradually increases throughout that last five years. Based on "Kazakhstan 2050 " strategy, the GDP share of SMEs should compose $50 \%$ to provide the stability of economic growth [13]. So, the main driving force for digital transformation in Kazakhstan is the government that offers reliable support for further development. According to Rakhimova, in 2018, a training program for entrepreneurs was launched to increase digital literacy, and over 15 thousand entrepreneurs have trained annually [14].

The SWOT analysis presented in Table 3 was performed to assess the state of SMEs in Kazakhstan. Overall, it can be said that SMEs have a high potential for future growth and technological improvement in case if support from government is appropriately performed and a qualification level of employees is increased. Moreover, it is necessary to pay more attention to the development of strategy, culture and operational effectiveness.

Table 1. SWOT analysis for Kazakhstan SMEs.

\begin{tabular}{|c|c|}
\hline Strengths & Weaknesses \\
\hline $\begin{array}{l}\text { The necessity for small-scale } \\
\text { seed capital; } \\
\text { Ability to provide quick } \\
\text { response to changes in market } \\
\text { conditions; } \\
\text { Possibility for rapid changes in } \\
\text { structure, strategy, culture if } \\
\text { improvements are needed; } \\
\text { Comparatively low amount of } \\
\text { investment and short payback } \\
\text { period }\end{array}$ & $\begin{array}{l}\text { Lack of active cooperation with } \\
\text { large enterprises; } \\
\text { Low qualification level of } \\
\text { entrepreneurs } \\
\text { Problems of access to financial } \\
\text { sources; } \\
\text { No clearly stated development } \\
\text { strategy or culture } \\
\text { Short life cycle; }\end{array}$ \\
\hline $\begin{array}{l}\text { Opportunities } \\
\text { Low barriers for market } \\
\text { penetration; } \\
\text { Strong support measures from } \\
\text { the government } \\
\text { Development of new products; } \\
\text { High capital turnover; } \\
\text { Further expansion }\end{array}$ & $\begin{array}{l}\text { Threats } \\
\text { High competition level between } \\
\text { domestic and foreign } \\
\text { companies; } \\
\text { High probability for low return } \\
\text { on investment for digitalization; } \\
\text { Limited market; } \\
\text { Vulnerability to the economic } \\
\text { crisis; }\end{array}$ \\
\hline
\end{tabular}

To sum up, the primary audience of this study is SMEs that needs to determine the level of readiness for digitalization, taking into account the basic low level of people and technology readiness. Moreover, it must consider that the primary focus for any SME is its customers and quality of its products, as even a slight decrease in customer satisfaction may fail the company because of a low amount of budget. The primary focus is on manufacturing and engineering companies in all industries.

\section{B. Design}

Based on the current state of SMEs in Kazakhstan, the following requirements can be stated for the digital maturity assessment model:

- the digital literacy level of both managers and employees;

- skills and qualification of company leaders;

- course towards digitalization said in company strategy and budget;

- level of technologies used;

- digitalization level of process and operations;

- the level of digitalization for the process of getting feedback on the product from customers, to track the satisfaction level of customers;

The dimensions and sub-dimensions of the model were developed based on the requirements of Kazakhstan SMEs. It has six dimensions and 15 sub-dimensions shown in Figure 1:

- People. The changes that the digital workplace may bring mostly affect employees working in the company, so it is necessary to check if they can adapt to alterations in the working environment, acquire new qualifications and skills. The readiness in this dimension is determined by the analysis of their skills in various areas and efforts of the company to acquire a new set of skills. Moreover, it is necessary to assess the knowledge sharing culture and cross-company collaboration.

- Leadership. Innovation management that is a crucial part of any transformation is measured in this case in addition to the personal integrity of leaders.

- Strategy. Digitalization is not only the mean to improve the products or processes, but also the opportunity of new business models development. In this dimension, strategy and investments are assessed.

- Technology. The dimension of technology evaluates the existence of modern ICT, utilization of machineto-machine communication

- Operations. As a result of the digitalization of company operations, it is possible to reach operational excellence with the enhancement of efficiency through greater automation, decrease the cost of product and thus customize them. It is necessary to measure supply chain management, information sharing and automation of processes.

- Product. This dimension is primarily concerned on the equipment of products with ICT components such as a sensor to collect data on their environment and communicate with higher-level systems to improve processes of production and guide them autonomously. The ICT add functionalities and data analytics in the usage phase (to gather feedback from customers) are assessed in this dimension. It also accounts for individualization of products. 


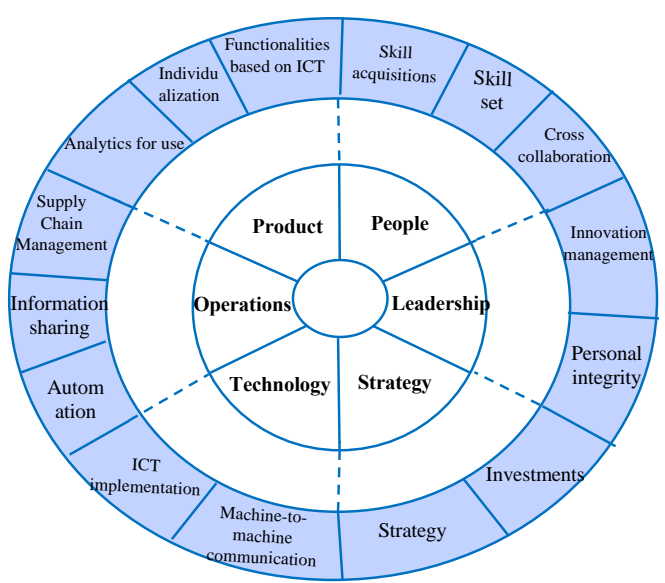

Figure 1. Model dimensions and sub-dimensions.

The model is divided into six maturity levels that assess the current readiness of the company. Each level has its description (shown in Figure 2) and requirements for movement to the next level. Zero level stands for outsiders who have not implemented any digitalization practices yet. The second level is the beginner who had some attempts for digital transformation; Level 2 is intermediate phase companies who have the infrastructure of operating smart technologies. Next level stands for experienced companies with vertical integration and network of manufacturing systems. Level 4 is for experts with horizontal integration through value network who already implemented big data analytics and machine learning. Moreover, finally, Level 5 is the top performers who performed the features of digital maturity and has continuous adaptation and self-optimization.

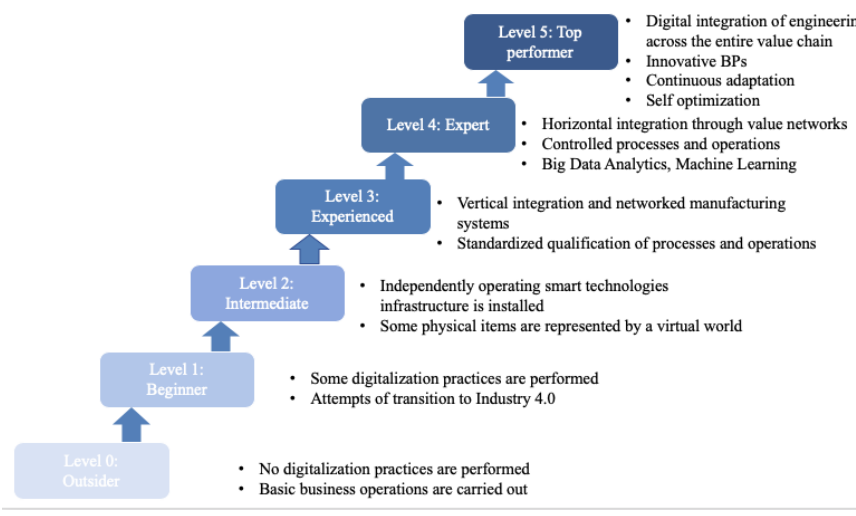

Figure 2. Model levels

\section{Populate}

The phase of the population is designed to consist of three steps: the aim of the first is to measure subdimensions with the use of a questionnaire, after this the maturity level is calculated and then represented visually with the provision of some further recommendations. It is necessary to mention that the employees of the companies are suggested to have basic knowledge of what is digital transformation and of its main features. Otherwise, it is highly advisable to conduct workshops for the provision of required knowledge.

The questionnaire with 16 questions is developed in order to measure the readiness of a company based on 16 sub-dimensions. The example of one of the questions that should be delivered to companies. The first part of the questionnaire is dedicated to the Assessment of dimensions. Each question has six types of answers that are: not exist, launched, in development, formulated, in implementation and implemented.

The next step is Assessment of weighting factor from not too important to very important. The scale from 1 to 4 is chosen to avoid the neutral answer that is often given in case if there is a middle answer. With this part of the questionnaire, the company has an opportunity to assess the importance of every factor for digital transformation by itself, as it is suggested to differ significantly from company to company and from industry to industry.

The next step of the population phase is the calculation of the maturity level. It is calculated the formula shown in Equation 1, where $M$ stands for maturity, $D$ - for dimensions, $I$-for item or subdimension, $g$ is a weighting factor, and $n$ is the number of maturity items. The equation is adapted from the study conducted by Schumacher et al. (2016).

$$
M_{D}=\frac{\sum_{i=1}^{n} M_{D I i} * g_{D I i}}{\sum_{i-1}^{n} g_{D I i}}
$$

The last phase is the Assessment of the company readiness for digital transformation and visual representations of the results. The team made the trial assessment for the industry company with the number of employees approximately 150 people. The team checked and validated it on the company employees. The managers of departments were asked to answer questions, and 12 answers were gathered. They had some issues and recommendations, and the model was improved based on them. The total score of each dimension is shown in Table 2. The results are also visualized with the aid of a radar chart in Figure 3 from level 0 to level 3. It can be seen that this company vitally needs to improve the areas of product and technology, while people, leadership and operations are at a comparatively high level. The overall maturity level can be assessed as Level 2 means that the company succeed in the installation of smart technology infrastructure that still operates independently from one another. The company needs to work towards the development of vertical integration and a system of networked manufacturing. 
Table 2. The assessment results of the company

\begin{tabular}{|c|c|c|c|c|}
\hline Dimension & Subdimension & Score & Weight & Total \\
\hline \multirow[t]{4}{*}{ Product } & & & & 1,09 \\
\hline & Analytics in usage phase & 1,20 & 2,30 & \\
\hline & Individualization & 1,34 & 0,00 & \\
\hline & $\begin{array}{l}\text { ICT based } \\
\text { functionalities }\end{array}$ & 0,92 & 1,50 & \\
\hline \multirow[t]{3}{*}{ People } & Skill acquisitions & 3,20 & 4,00 & 2,30 \\
\hline & Skill set & 1,40 & 4,00 & \\
\hline & Cross collaboration & 2,30 & 3,5 & \\
\hline \multirow[t]{2}{*}{ Leadership } & Innovation management & 1,32 & 2,90 & 2,47 \\
\hline & Personal integrity & 3,43 & 3,50 & \\
\hline \multirow[t]{2}{*}{ Strategy } & Investments & 2,45 & 4,00 & 2,08 \\
\hline & Strategy & 1,65 & 3,50 & \\
\hline \multirow[t]{2}{*}{ Technology } & $\begin{array}{l}\text { Machine-to-machine } \\
\text { communication }\end{array}$ & 0,43 & 2,40 & 0,71 \\
\hline & ICT functions & 0,98 & 2,50 & \\
\hline \multirow[t]{3}{*}{ Operations } & Automation & 3,21 & 3,60 & 2,70 \\
\hline & Information sharing & 2,54 & 3,20 & \\
\hline & SCM & 2,32 & 3,40 & \\
\hline
\end{tabular}

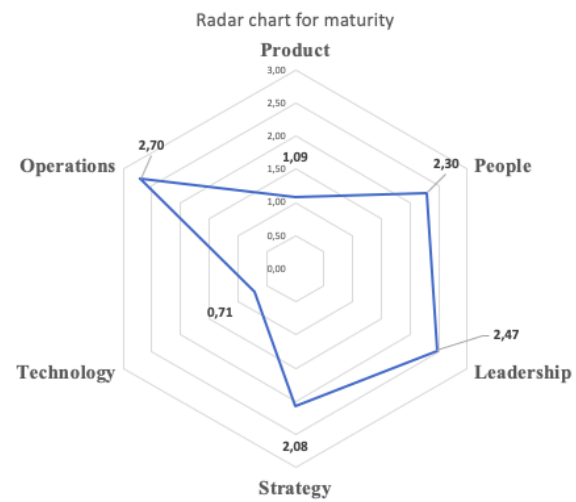

Figure 3. The radar chart for the digital maturity of the company

\section{CONCLUSION}

In this paper, the digital maturity and readiness model for Kazakhstan SMEs was proposed based on the analysis of existing digital maturity assessment models and the current state of SMEs in Kazakhstan. The main requirements for the digital maturity model were identified; the model was developed and validated through an interview with a company. The trial maturity assessment was conducted, and the results were obtained and visualized. The model has proven itself as applicable for Kazakhstan SMEs and allowed the provision of recommendations for further actions to achieve the next level of digital maturity.

There are still numerous areas for improvement of the model. It is necessary to assess the role of government in the digitalization of SMEs, as it is extremely valuable for developing countries. The model should be further refined, and the guideline for adopting by Kazakhstan SMEs should be developed.

\section{ACKNOWLEDGEMENT}

The authors would like to thank Nazarbayev University for funding this article under the Faculty
Development Competitive Research Grant Program (FCDRGP) Grant No. 110119FD4524.

The authors would like to express their gratitude to the participants of the assessment model for spending their time and providing valuable feedback and information.

\section{REFERENCES}

[1] M. Rachinger, R. Rauter, C. Müller, W. Vorraber, and E. Schirgi, "Digitalization and its influence on business model innovation," Journal of Manufacturing Technology Management, vol. 30, no. 8, pp. 1143-1160, Sep. 2019.

[2] S. Mittal, M. A. Khan, D. Romero, and T. Wuest, "A critical review of smart manufacturing \& Industry 4.0 maturity models: Implications for small and medium-sized enterprises (SMEs)," Journal of Manufacturing Systems, vol. 49, pp. 194-214, 2018.

[3] N. Oregan and A. Ghobadian, "Re-visiting the strategyperformance question: an empirical analysis," International Journal of Management and Decision Making, vol. 5, no. 2/3, p. 144, 2004.

[4] "Annual report on SME Kazakhstan," atameken.kz, 2008 [Online].

Available: https://atameken.kz/uploads/docs/reminders/2019-04/otchet-2kvartal-2018 1555049568.pdf

[5] F. Blatz, R. Bulander, and M. Dietel, "Maturity Model of Digitization for SMEs," 2018 IEEE International Conference on Engineering, Technology and Innovation (ICE/ITMC), 2018.

[6] "The Connected Enterprise," RockwellAutomation.com. [Online]. Available

:https://literature.rockwellautomation.com/idc/groups/literature/do cuments/wp/cie-wp002_-en-p.pdf. [Accessed: 13-Jun-2020].

[7] S. R. Hamidi, A. A. Aziz, S. M. Shuhidan, A. A. Aziz, and M. Mokhsin, "SMEs Maturity Model Assessment of IR4.0 Digital Transformation," Advances in Intelligent Systems and Computing Proceedings of the 7th International Conference on Kansei Engineering and Emotion Research 2018, pp. 721-732, 2018.

[8] C. Leyh, T. Schäffer, K. Bley, and S. Forstenhäusler, "Assessing the IT and Software Landscapes of Industry 4.0-Enterprises: The Maturity Model SIMMI 4.0," Information Technology for Management: New Ideas and Real Solutions Lecture Notes in Business Information Processing, pp. 103-119, 2017

[9] J. Ganzarain and N. Errasti, "Three stage maturity model in SME's toward industry 4.0," Journal of Industrial Engineering and Management, vol. 9, no. 5, p. 1119, 2016.

[10] "Business Intelligence Maturity Models: An Overview," D'Atri, Ferrara and Spagnoletti (eds.) Proceedings of the VII Conference of the Italian Chapter of AIS, Naples, Italy, 2010.

[11] "Digital Kazakhstan - official source of state program ..." [Online]. Available: https://digitalkz.kz/en/. [Accessed: 13-Jun2020].

[12] Report Of The Minister Of Industry And Infrastructure Development Of The Republic Of Kazakhstan at The International Forum "Digital Agenda In The Age Of Globalization" (2018, March 12). miid.gov.kz, [Online]. Available: http://miid.gov.kz/ru/pages/doklad-ministra-mir-rk-namezhdunarodnom-forume-cifrovaya-povestka-v-epohuglobalizacii. [Accessed: 13-Jun-2020].

[13] Staff Report in Business on 21 November 2019, "Kazakhstan's digital transformation has a $\$ 578$ million positive effect ," The Astana Times, 21-Nov-2019. [Online]. Available: https://astanatimes.com/2019/11/kazakhstans-digitaltransformation-has-a-578-million-positive-effect/. [Accessed: 13Jun-2020].

[14] S. A. Rakhimova and M. M. Turgumbekova, "Programs Of Government Support For Sme In The Republic Of Kazakhstan And Measures To Enhance Their Efficiency," Series Of Social And Human Sciences, vol. 6, no. 322, pp. 233-240, 2018.

[15] A. Schumacher, S. Erol, and W. Sihn, "A Maturity Model for Assessing Industry 4.0 Readiness and Maturity of Manufacturing Enterprises," Procedia CIRP, vol. 52, pp. 161-166, 2016 
2021-06-29

\section{Digital maturity and readiness model for Kazakhstan SMEs}

Yezhebay, Assel

IEEE

Yezhebay A, Sengirova V, Igali D, et al., (2021) Digital maturity and readiness model for

Kazakhstan SMEs. In: 2021 IEEE International Conference on Smart Information Systems and

Technologies (SIST), 28-29 April 2021, Nur-Sultan

https://doi.org/10.1109/SIST50301.2021.9465890

Downloaded from Cranfield Library Services E-Repository 